\title{
POR LA RENOVACIÓN DE UN (NO) CANON. CRÍTICAS Y NARRADORAS EN EL SIGLO XXI, MÉXICO Y DIÁSPORA
}

Adriana Pacheco Roldán ${ }^{1}$ : Universidad de las Américas Puebla. México. adriana.pacheco@udlap.mx

\section{RESUMEN}

El propósito de esta investigación es hacer un análisis de la producción y temática en la narrativa contemporánea de mujeres en México, para recuperar algunas obras de escritoras con formación universitaria o estudios de postgrado. La intención es revisar de qué manera la formación crítica y la producción literaria dialogan y funcionan como conducto de sus propuestas epistemológicas para denunciar y recusar esquemas de poder, promover la equidad de género, o proponer nuevas representaciones estéticas. El estudio parte del trabajo de cuatro escritoras representando las generaciones de los 1970s a los 1980s: Guadalupe Nettel (México 1973), Marina Herrera (Saltillo 1977), Verónica Gerber (México 1981) y Valeria Luiselli (México 1983). La muestra anterior fue seleccionada debido a que sus obras responden a una renovada visión en la perspectiva de teorías críticas más contemporáneas como los estudios culturales y los estudios de género postcoloniales, y a una innovación creativa con nuevas propuestas estéticas. Este trabajo es la primera fase de un proyecto que eventualmente integrará parte de un texto didáctico para la enseñanza del análisis textual en el aula de educación universitaria o preparatoria, desde una perspectiva de género, social y cultural que se ajuste más a la circunstancia contemporánea de la mujer en México y a la enseñanza de la literatura.

\section{PALABRAS CLAVE}

Narrativa - México - Mujeres - Academia - Género - Feminismo postcolonial Estudios culturales - Crítica contemporánea - Biopolíticas

\section{FOR THE RENEWAL OF A (NON)CANON. CRITICS AND NARRATORS IN THE 21st CENTURY, MEXICO AND DIASPORA}

\section{ABSTRACT}

This study aims to analyze the narrative production of contemporary Mexican women writers in order to shine light on the work of those with college degrees in

1 Adriana Pacheco Roldán, PhD: Universidad de las Américas Puebla. México adriana.pacheco@udlap.mx 
the humanities, with the goal of understanding how a formal background on literary criticism relates to literary production and how their writings act as a conduit for epistemological proposals aiming to denounce and recuse power structures, promote gender equality or offer new aesthetical representations. I base the study on the work of four writers representative of the generations of the 1970s and 1980s: Guadalupe Nettel (México, D.F. 1973), Marina Herrera (Saltillo 1977), Verónica Gerber (México, D.F. 1981) y Valeria Luiselli (México, D.F. 1983), sample which I selected because their works all share a marked creative innovation, put forward new aesthetic proposals, and subscribe to contemporary and renewed perspectives on critical theories, such as cultural studies, and post-colonial gender studies. This work is a first phase within a broader project that will eventually yield a chapter in a textbook meant for a high school or college instruction of textual analysis from gender, social and cultural perspectives that will better fit the contemporary circumstances of women and the way literature is taught in Mexico.

\section{KEYWORDS}

Narrative - Mexico - Women - Academy - Gender - Post-colonial feminism Cultural studies - Contemporary criticism - Biopolitics

\section{INTRODUCCIÓN}

La visibilidad de que gozan algunas escritoras en el contexto contemporáneo, es el resultado de una corta tradición literaria y un largo proceso de lucha, que aún no está resuelto. Es, como lo dice Sylvie Didour Aupetit, el resultado de una larga "invisibilidad social del sujeto" (1999, p. 1), dentro de un país en donde los espacios para la publicación están atados a una serie de dinámicas de discriminación. Muchas de las escritoras que han destacado en la historia de la literatura contemporánea en México han estudiado en universidades públicas o privadas, como Rosario Castellanos (México 1925-1974) o Inés Arredondo (Culiacán 1928-1989). Esto habla de una comunidad de mujeres que en su múltiple función como docentes, estudiantes, investigadoras o activistas sociales ven en el ejercicio de la escritura otro medio para hacer valer sus ideas o cuestionar su realidad. Otra característica que las agrupa es su cosmopolitismo por haber vivido, algunas de ellas en diversos países tanto por su situación personal como por la internacionalización de la educación superior, lo que genera tanto una escritura centrada en lo local, como otra en donde "los escenarios internacionales se llevan de la mano con un lenguaje menos regionalista" (Nettelen Hind, 2013, p. 332). Esa mirada que ve a México a la distancia aporta al mercado literario un imaginario que amplía los temas sociales, cuestiona las categorías hegemónicas, y permea marcos teóricos y referentes literarios. Ya no solo están Octavio Paz, Juan Rulfo o Gilberto Owen, sino también Franz Kafka o Stéphane Mallarmé. En cuanto a los temas, la intención de sus obras es pasar por encima de fronteras geográficas, sociales, y políticas que se han enraizado en el imaginario colectivo, lo que pone en evidencia las deficiencias de la gran metáfora orgánica que significan México, Latinoamérica y el mundo. 
Sin embargo, al mismo tiempo que algunas han ganado reconocimiento, sufren de una gran invisibilidad que les impide integrarse como parte de una nueva generación con valiosas propuestas críticas, estéticas y teóricas. Como bien es sabido, a lo largo de la historia crítica de la literatura a nivel continental existe un limitado reconocimiento de las mujeres que escriben. Obras como la de Pedro Henríquez Ureña, Las Corrientes Literarias en la América Hispánica (México 1945); Anderson Imbert y su Historia de la Literatura Hispanoamericana (México 1954), o José Luis Martínez y La Expresión Nacional (México 1984), son prueba de ello. Ediciones críticas más contemporáneas como Nueva Narrativa Hispanoamericab (Madrid 1999) de Donal L. Shaw o Caminata por la narrativa latinoamericana (Xalapa 2002) de Seymour Menton continúan concentrándose en escritoras como Rosario Castellanos o Inés Arredondo (Culiacán 1928-1989) y, del Posboom, Elena Garro (Puebla 1937-1998), Elena Poniatowska (París 1932), Guadalupe Loaeza (México 1946) o Ángeles Mastreta (Puebla 1949). Sin lugar a dudas, todas estas escritoras son parte de un corpus literario fundamental en el estudio de las letras mexicanas, pero hoy, en el siglo XXI, siguen siendo el único referente de la escritura contemporánea escrita por mujeres en México. Prueba de ello son los programas de estudio de preparatorias, universidades, talleres de lectura y escritura, los anaqueles de las librerías, los resultados de búsquedas en internet, el imaginario mismo de las personas en donde otros nombres nunca aparecen. La revisión e incorporación de ampliación de este (no) canones urgente para incorporar nuevas voces, obras, temas, estéticas, desde el sentido crítico de la teoría literaria.

\section{METODOLOGÍA}

La metodología se realiza desde dos ángulos: un estudio cualitativo del panorama actual en cuanto a la escritura de mujeres partiendo de una muestra representativa de obras de escritoras. Se localiza en él las que cuentan con estudios superiores y se hace una reflexión sobre sus tendencia de género literario, temas y contextos. En segundo lugar, se realiza un análisis textual y comparativo de la dimensión dialéctica de algunos textos desde teorías criticas de género, cultura y postcolonialidad en relación a la circunstancia de México y Latinoamérica.

La muestra general con la que se realiza el estudio comprende 24 escritoras nacidas entre 1940 y 1980. El análisis comparativo de obras literarias se enfoca en4 de ellas con formación superior y que corresponden a:

- Generación de 1970: Guadalupe Nettel (México 1973) y Marina Herrera (Saltillo 1977)

- Generación de 1980: Verónica Gerber (México 1981) y Valeria Luiselli (México 1983)

\section{ANÁLISIS Y DISCUSIÓN}

\subsection{Antecedentes}


Se localiza la década de los 1970s como parte aguas en el incremento de la incorporación de la mujer a la educación superior. Esto es el resultado de los movimientos feministas que se dan a nivel nacional e internacional, así como la apertura en la década de los 1990s de instituciones que promueven los estudios de género como el PUEG (Programa Universitario de Estudios de Género), el PIEM (Programa Interdisciplinario de Estudios de la Mujer) y la fundación de las revistas Fem(1976)y Debate Feminista (1990).Este impulso por revisar los derechos legales, reproductivos y sociales de la mujer, da las condiciones a un cambio de paradigma y permite a muchas mujeres incorporarse no solo a la educación básica sino a la educación superior. De acuerdo al INEGI tenemos que en 1970, de una población femenina de 13,230,305, el 1.2\% de las mujeres tenía educación superior. En 2000 los números cambian a 32,798,814 con el $9.4 \%$, y para el año 2010, de 40,767,055, el porcentaje de mujeres que llegan a esta es de $15.9 \%$. La tabla a continuación muestra de manera más gráfica lo anterior.

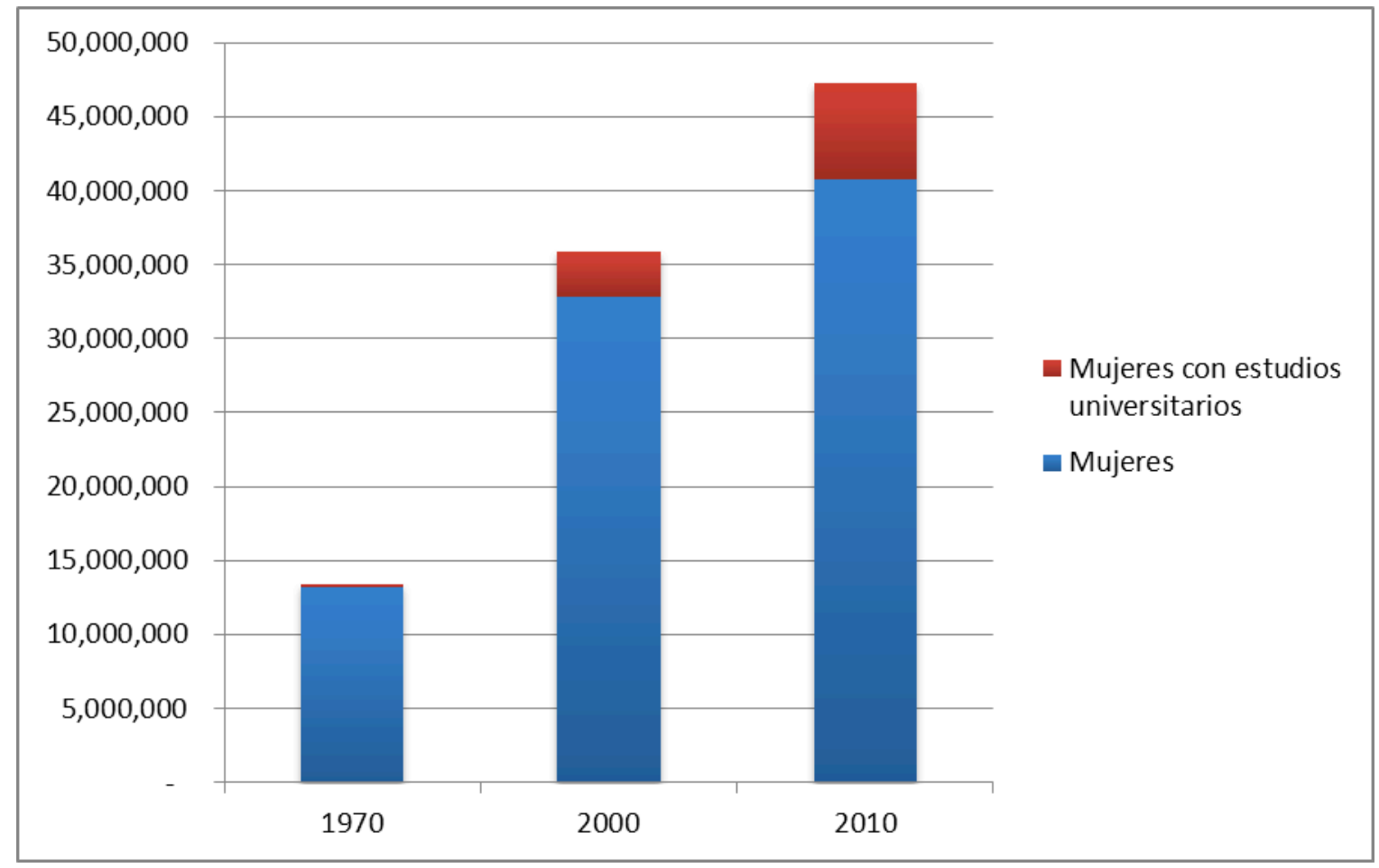

Gráfico 1: Mujeres con estudios universitarios. INEGI “Características educativas de la población. 2015.

Sin embargo, es difícil cuantificar los porcentajes de estudiantes en las áreas de humanidades y ciencias. Dentro de la primera área, ¿cuántas estudiaron Literatura, Letras?¿Qué porcentaje finalizó sus estudios y obtuvo un certificado? De esas, ¿cuántas ejercen su profesión? Y finalmente ¿Cuántas se inclinaron a la escritura creativa? Lo que queda claro es que viendo la curva de crecimiento en los 40 años 
que presenta la tabla, se puede concluir que en proporción, el incremento de mujeres que estudiaron es notable, lo que debió haber impactado de manera proporcional al número de escritoras. De alguna manera la producción de la industria editorial puede servir como referente, para tener una idea más o menos aproximada de la situación de obras escritas por mujeres en el mercado. Sin embargo esto también puede ser ambiguo, debido a que muchas mujeres no logran publicar sus trabajos ni llegar a un mercado que consuma sus obras. En la actualidad las opciones de Open Access abren otro espacio para la publicación que algunos escritores están aprovechando.

Esta es precisamente una de las problemáticas a las que más se enfrentan las mujeres $\mathrm{y}$, aunque las conexiones, la tenacidad, los premios literarios, el respaldo de una universidad, o un buen agente puedan ser la fórmula para llegar a una editorial, el camino es arduo. Yanitzia Canettidice sobre esto que "Las editoriales ya tienen preparadas cartas-modelo con respuestas como la que sigue: "hemos recibido su obra pero desafortunadamente no se ajusta al perfil de nuestra editorial". (117)En los últimos años, para las que viven en Estados Unidos la situación se ha mejorado debido al auge de lo que se conoce como la "New Latino Writing" - La Nueva Escritura Latina - y que ha dando un incremento de estas en el mercado (Rivera Garza The New).España contribuye también con su difusión en casas como Anagrama (Barcelona) y Editorial Sexto Piso (México/Madrid)y Tusquets Editores (México/Barcelona). En México quienes publican estas obras pueden dividirse entre editoriales privadas, localizadas principalmente en la Ciudad de México como Océano, Santillana, con su colección Punto de lectura, Alfaguara, y Planeta. Algunas de las editoriales más pequeñas o en el interior del país son Nitropress (Sonora), Ediciones Era (México), Editorial Aldus (México), Difocur (Sinaloa), Ficticia (México), La Fragua (Coahuila), Ediciones Era (México), y Editorial Almadía (México).Un tercer grupo lo integran las universitarias y organismos estatales o federales como la UNAM, Consejo Nacional para la Cultura y las Artes en su programa Tierra Adentro, o Programa Editorial de Sonora (México).

El sexismo al que se enfrentan las mujeres en la industria editorial no es privativo de México. \#Readwomen 2014 movimiento creado por Joanna Walsh es un ejemplo de acciones conjuntas en contra de la "disparidad en la presencia de hombres y mujeres en espacios de difusión cultural en lengua inglesa" (Damián, 2014). Su objetivo es concientizar acerca del gran vacío de espacios de publicación y promoción para las mujeres, así como de la crítica sistemática con la que se etiqueta la literatura "femenina" - si existe tal cosa-como "frívola y poco seria". Pero, en cuanto a las escritoras que sí publican, este trabajo propone una muestra representativa que se presenta a continuación.

\subsection{Visión orgánica y cohesión generacional. Escritoras entre 1930 y 1980}

En México el fenómeno del Boom - un movimiento literario de esencia masculina que agudiza aún más la exclusión de la escritora y que se da de en los 1970s y 1980s - ponelos ojos del mundo en Latinoamérica y el mercado editorial se plaga de obras los escritores que lo forman. Jorge Volpilo describe como la tabla de salvación para los vendedores de libros (2008, p. 104). Rosario Castellanos e Inés Arredondo entran como antecesoras de este grupo, la primera dentro de los 1950s y la segunda 
en los 1970s. Es el posboom y la literatura testimonial en donde encuentra espacio una reducida pero importante generación de escritoras que nacen entre los 1930s a los 1950s como Elena Poniatowska (París 1932), Guadalupe Loaeza (México 1946), Ángeles Mastreta (Puebla 1949), Laura Esquivel (México 1950), Esther Hernández (México 1952), Carmen Boullosa (México 1954) y Ethel Krauze (México 1954). Esta generación recurre al género testimonial para hablar de la problemática social y la falta de legalidad de las acciones de las instituciones. Para otras el recurso de la literatura fragmentaria, en donde la conciencia se disuelve como está sucediendo con la legalidad en el país, es el medio para recusar la realidad y hacer una crítica desde la función estética de la literatura, sin hacer uso de las mismas herramientas de lo que entienden como el opresor. Donald L. Shaw hace referencia a esto en su análisis sobre la obra de la escritora chilena Damiela Eltity dice que "Surge la pregunta: ¿cómo criticar el poder, desde el punto de vista de la mujer, sin caer en el arte testimonial y de denuncia tan amado por la izquierda militante? (Shaw, 1999, p. 347)2.

El neoliberalismo, la globalización, los movimientos feministas y gay-lesbian marcan a las tres siguientes generaciones. Algunos de los trabajos de escritoras de los 1960s a 1980s permean una crítica del poder que ya no queda reservada solo al patriarcado, sino a un poder bifurcado en muchos otros que tienen más que ver con el mercado, los sistemas globalizados, y las fronteras, entre otros. La vida social y política que describen tiene una constante "marca del neoliberalismo y de la velocidad de la circulación del capital" (Noemí, 2008, p. 88). En sus obras se observa tanto una redimensión del erotismo, el deseo, el cuerpo, recobrando voces de pioneras como María Luisa Bombal (Viña del mar 1910) entre otras. De igual forma se observa una importante presencia de un narrador homodiegético, que desde dentro de la historia habla de temas como la soledad o la locura. Algunos ejemplos de escritoras mexicanas que nacen en los 1960s son: Rosa Beltrán (México 1960), Adriana González Mateos (México 1961), Ana Clavel (México 1961), Cristiana Rivera Garza (Matamoros 1964), y Susana Pagano (México 1968).

De las nacidas en los 70s, Emily Hinddice en su libro, La Generación XXX: Entrevistas con veinte escritores mexicanos nacidos en los 70 . De Abenshus han a Xonocostleque una característica común que estás tienen es un "cierto cinismo frente a la autoridad y las instituciones" (2013, p. 20).Esta es una generación que está marcada por el temblor de 1985, la violencia masiva en contra de las mujeres, denominada por Marcela Lagarde "feminicidios", como la que se da en Ciudad Juárez y, en la primera década del siglo XXI, la guerra en contra del narcotráfico. Algunos nombres representativos son: Viviana Abenshushan (México 1972), Liliana Blum (México 1974), Guadalupe Nettel (México 1973), Marcela Turatti (México 1974), Cristina Rascón Castro (Cd. Obregón 1976), Marina Herrera (Saltillo 1977). Por supuesto que a estas se suman las voces de protesta de escritoras de generaciones anteriores como la obra de Esther Hernández

\footnotetext{
${ }^{2}$ Dianel Eltit tiene varias obras en donde a través del cuerpo femenino denuncia la dictadura en Chile. La cita de Shaw muestra una de las lecturas de la crítica masculina en donde la escritora se presenta frágil, vulnerable o sesgada y regida por una visión masculina, cosa que no responde al perfil de Eltit, quien ha mostrado en sus trabajos un manejo de los temas de la represión desde distintos géneros literarios.
} 
Palacios Diario de una madre mutilada (Ficticia 2012).

La generación de los 1980s, conocida como la generación " $Y$ ", del milenio, o globalizada revela otras problemáticas. Los temas de estas hablan de soledad y aislamiento urbano como una nueva alternativa al antes glamoroso flaneur de Baudelaire, el cosmopolitismo. El espacio social de las nacidas en esta década define al sujeto mediante prácticas indisociables de las tecnologías de la información y la comunicación. Jorge López Cuenca hace la pregunta ¿Qué tipo de sujeto habla, escribe o se comunica en la "era de la información?" (12). Se observa una importante tendencia de las escritoras al género del cuento corto, a experimentar con narraciones fragmentadas que son, más que relatos, pequeñas capsulas de filosofía y de reflexión. Menciono acá algunos nombres como: Verónica Gerber (México 1981), Brenda Lozano (México 1981), Fernanda Melchor (Veracruz 1982), y Valeria Luiselli (México 1983).

La revisión hecha en esta sección recurre a una catalogación generacional de las escritoras, lo cual termina invariablemente por ser excluyente y reduccionista, por lo que de alguna manera replica los discursos hegemónicos que el patriarcado siempre ha impuesto. Sin embargo, como José Luis Martínez dice en su libro La Expresión Nacional (México 1984) el análisis desde la teoría de las generaciones nos da una "visión más orgánica" y una idea sobre "la fuerte cohesión que ha existido entre el escritor y la sociedad" (1984, p. 445). Viendo los nombres antes mencionados, pueden localizarse una importante cantidad de escritoras con estudios superiores que están además involucradas en la academia o la docencia. En su gran mayoría estas proceden de instituciones como la UNAM o de universidades extranjeras, en particular los Estados Unidos. Los campos que más se observan son los de las humanidades, el periodismo y algunas artistas plásticas, como en el caso de Verónica Gerber. La distribución queda de la siguiente manera:

\begin{tabular}{|c|c|c|}
\hline Nombre & Año nac & Estudios \\
\hline Inés Arredondo & 1921 & UNAM \\
\hline Rosario Castellanos & 1925 & UNAM \\
\hline Elena Poniatowska & 1932 & - \\
\hline Guadalupe Loaeza & 1946 & - \\
\hline Ángeles Mastreta & 1949 & UNAM \\
\hline Laura Esquivel & 1950 & Escuela Normal de Maestros \\
\hline Esther Hernández & 1952 & Universidad Veracruzana \\
\hline Carmen Boullosa & 1954 & - \\
\hline EthelKrauze & 1954 & UNAM \\
\hline Rosa Beltrán & 1960 & Universidad de California en Los \\
\hline
\end{tabular}




\begin{tabular}{|c|c|c|}
\hline & & Ángeles \\
\hline $\begin{array}{l}\text { Adriana González } \\
\text { Mateos }\end{array}$ & 1961 & Universidad de Nueva York \\
\hline Ana Clavel & 1961 & UNAM \\
\hline Cristina Rivera Garza & 1964 & UNAM \\
\hline Susana Pagano & 1968 & SOGEM \\
\hline Viviana Abenshushan & 1972 & UNAM \\
\hline Liliana Blum & 1974 & Tec de Monterrey \\
\hline Guadalupe Nettel & 1973 & $\begin{array}{r}\text { École des Hautes Études en Sciences } \\
\text { Sociales in Paris }\end{array}$ \\
\hline Marcela Turatti & 1974 & Universidad Iberoamericana México \\
\hline Cristina Rascón Castro & 1976 & Universidad de Osaka \\
\hline Marina Herrera & 1977 & Universidad de Saltillo \\
\hline Verónica Gerber & 1981 & La Esmeralda, UNAM \\
\hline Brenda Lozano & 1981 & Universidad Iberoamericana México \\
\hline Fernanda Melchor & 1982 & Universidad Veracruzana \\
\hline Valeria Luiselli & 1983 & Universidad de Columbia. \\
\hline
\end{tabular}

Si se observa en la tabla anterior, una tercera parte, el 33\%, estudiaron en la UNAM; el $20 \%$ en universidades fuera del país. Dos escritoras vienen de la Universidad Veracruzana y el resto de una mezcla de casas de estudio privadas y públicas. Para el análisis textual, se toman de esta relación cuatro, Guadalupe Nettel, Marina Herrera, Verónica Gerber y Valeria Luiselli, cuyos trabajos, todos heterogéneos entre sí, muestran tanto elementos de una larga tradición literaria, como un esfuerzo que busca desvincularse de imaginarios que sirvieron en otro momento como común denominador, considerados como leitmotiv de una escritura "femenina". La formación de todas ellas se permea en sus historias en referentes a personajes de la literatura, el arte o la historia y en el uso de estrategias que refieren al lector a Kafka, Mallarmé, Kundera, entre otros. Las cuatro tienen una producción en donde la identidad del sujeto se presenta como resultado de una realidad individual que deja marcas visibles en los cuerpos tanto físicos como emocionales. Las escritoras de estas generaciones permean parte de su biografía en sus obras. 


\section{DISCUSIÓN}

\subsection{Generación de 1970. Guadalupe Nettel y Marina Herrera}

Marina Herrera (Saltillo 1977) tiene formación en letras con una licenciatura en Lengua y Literatura Españolas. En una entrevista publicada en "El papel del escritor" Ediciones global 4 febrero 2008 dice que uno de sus autores favoritos es Juan Rulfo, influencia que se aprecia en su libro El cuerpo incorrupto (Lafragua 2008), en donde el tema de la muerte constituye la línea narrativa de los 13 cuentos que contiene el libro. Guadalupe Nettel (México 1973) tiene una licenciatura en la UNAM y un doctorado en la École des Hautes Études en Sciences Sociales de París. Ganadora de varios premios entre ellos el de Narrativa Breve Ribera del Duero y el Herralde. Nettel aborda en parte de su obra crítica el tema de lo mágico como en "Presencia cotidiana",o el de la libertad como en su trabajo de investigación doctoral sobre Octavio Paz. Su novela El cuerpo en que nací (Anagrama 2011) es una historia autobiográfica.

\subsection{Generación de 1980. Valeria Luiselli y Verónica Geber}

Valeria Luiselli (México 1983) es estudiante de doctorado en la Universidad de Columbia en donde su proyecto, de acuerdo a su página en esta casa de estudios, son las prácticas de traducción en la época post-revolucionaria en la ciudad de México, periodo que abarca a un cantidad importante de intelectuales, escritores y artistas como Gilberto Owen. Owen es precisamente uno de los personajes de su novela Los ingrávidos (Sexto Piso 2011). Su primer libro es Papeles falsos (Sexto piso 2010), más tarde publica La historia de mis dientes (Sexto piso 2013), entre otros. Está catalogada una de los mejores escritoras del momento.

Verónica Gerber (México 1981) muestra su formación en Artes visuales en la ENPEG, La Esmeralda y tiene una maestría en Historia del Arte de la UNAM. Colabora con ensayos en diversas revistas. Como artista típica del siglo XXI, sus escritos y parte de su obra plástica se puede descargar por Internet, ellos reflejan el diálogo que se da entre ambos artes. Su libro Mudanza tiene dos textos autobiográficos: el que estudia este trabajo "Ambliopía” y "Ambigrama” (Gerber, 2011)

\subsection{Algunos tópicos y géneros en las obras}

¿Cuáles son los temas “de mujeres”? pregunta Gabriela Damián Miravete (2014), con lo que contesta con una pregunta al estereotipo impuesto a la escritura de estas. Tradicionalmente se considera que las mujeres escriben temas que tienen que ver con su problemática emocional y su papel dentro del matrimonio y la maternidad, una "escritura femenina" (Cixous, Laugh 347). Este paradigma es el que se busca de construir para borrar una etiqueta que en muchas ocasiones aleja a las escritoras de los editores y los lectores, o que las encasilla en una categoría inamovible. Las obras de Nettel, Herrera, Luiselli y Gerber dejan en evidencia que los temas pueden ser otros, que se presentan desde diversas maneras o que no son leitmotivs obligados de su escritura. Por lo cual, también el marco crítico con que se les lee debe alejarse de una ginocrítica que iguala a todas las mujeres (Golubov, 2011,p. 4). A continuación 
presento un análisis comparativo de obras de las cuatro escritoras de estudio para mostrar sus distintos acercamientos a tres temas: la corporalidad, la fragmentación del cuerpo y el ejercicio de la creación literaria.

\subsubsection{Corporalidad. "El cuerpo corrupto" y "Eucaristía" de Marina Herrera}

Los estudios sobre las políticas de cuerpo-biopolítica-iniciados desde la crítica de Michel Foucault y Judith Butler, puso en el centro del discurso la importancia que tiene la corporalidad para la creación de la identidad y la modelación de la subjetividad. Teresa de Laurentis habla de un cuerpo colonizado construido a partir de la mirada masculina, que por lo tanto debe ser repensado desde fuera del "monopolio de poder y conocimiento de masculino heterosexual" (De Laurentis, 1984, p. 163). Así sucede en “El cuerpo corrupto" y “Eucaristía” de Mariana Herrera publicados en su libro El cuerpo corrupto (La fragua: Coahuila, 2007). Ambos relatos se centran en el cuerpo femenino para cuestionar el estereotipo de la mujer angelical. En la obra se observa una fuerte influencia del realismo mágico o lo real maravilloso del Boom, pero presentado desde lo grotesco. Sus personajes femeninos rompen con el código específico de la producción cultural de una sociedad heterosexual con una mujer doméstica y subordinada al control masculino.

"El cuerpo incorrupto", presenta la muerte de Mati, la matrona de un prostíbulo, cuyo cuerpo sufre una transformación milagrosa hasta quedar intacto en una especie de santificación corporal "A los quince días de su muerte, en su frente y nariz todavía nacían perlas de sudor que desprendían un aroma de jazmines y rosas" (2007, p. 48).Al darse cuenta de esto, la colocan en una vitrina para que la gente pueda verla, desde donde las "chicas" de la casa pasan a recibir la bendición "Frente a su vitrina nos persignamos antes de iniciar nuestras labores nocturnas y contemplamos su rostro piadoso que parece decir aún: Vamos, chicas, complazcan a los clientes, sonrían y déjense tocar" (2007, p. 49). En el imaginario colectivo, la prostituta es siempre una figura ambivalente y cargada de significado. Por un lado, es un elemento necesario para la sociedad y por el otro representa la "decadencia de la sociedad". En la historia, Herrera recurre al tropo cristiano, tan presente en la retórica de San Juan de la Cruz y Santa Teresa de Ávila, y al paradigma de la separación del cuerpo y el alma como medio para alcanzar el estado de perfección y la salvación. Esto ayuda a mostrar otro ángulo del ejercicio de la prostitución y de construir el estereotipo de la prostituta.

El segundo cuento, "Eucaristía" publicado en el mismo libro, muestra nuevamente la conexión entre cuerpo femenino y sacralidad, transmutando el cuerpo de Jesucristo al de la mujer. El hombre, en su función de sacerdote, es el que ejecuta el rito, mostrando el poder patriarcal, pero principalmente la mirada tan particular con la que observa la corporalidad femenina. La historia presenta a Otilia, una mujer de proporciones desmesuradas que permanece en su casa hasta que el narrador, un hombre que la corteja, decide sacarla de esta y casarse con ella "Un sacerdote nos casó en su habitación. Luego abrimos un boquete en la pared y un camión de mudanzas la trajo con todo y cama mecánica a nuestro hogar"(2000, p. 75). No es aleatorio que Herrera use el vocablo "hogar" en este pasaje, con el que se refiere a la 
unidad orgánica impuesta como "natural" en la sociedad heterosexual. La historia continua con la descripción del cuidado extremo que el esposo tiene de Otilia, y descripciones de sus encuentros sexuales que se presentan casi como místicos "El templo en los brazos de Otilia me acercaba a Dios, era un conducto hacia mi salvación". Un día el protagonista decide que su cuerpo será medio para llegar a la santidad, por lo que la ata a la cama imitando la imagen de la crucifixión, para después descuartizarla. En el momento en que su "corazón de vaca" (2000, p. 78) se detiene, el narrador determina que Otilia ha partido "a las alturas, beata, canonizada y santa en un solo acto" (2000, p. 78). Después almacena su carne y la refrigera para poder comerla en un "rito religioso comulgar con su cuerpo, hacerla mía en cada bocado" (2000, p. 78). La representación que Herrera hace en esta historia de la sexualidad en una intersección con la religión agrega el elemento de lo grotesco para deconstruir dos instituciones hegemónicas: la Iglesia y la Familia. La unión entre los cuerpos en una comunión, lleva al lector a referentes que le son familiares en una retórica cristiana que ha "purificado" al cuerpo femenino y elevado la institución del matrimonio al punto de sacramento.

\subsubsection{La fragmentación del cuerpo. "Ambliopía" de Verónica Gerber y "Ptosis" de Guadaluppe Nettel}

Otras dos obras que abordan la representación del cuerpo son los cuentos "Ptosis" publicada en Pétalos(Anagrama 2008) de Guadaluppe Nettel y "Ambliopía" publicado en Mudanza (Auieo2010) de Verónica Gerber. En ellos los individuos existen a través de una parte de sus cuerpos que domina al todo. Son cuerpos fragmentados y por lo consiguiente abyectos y grotescos, en el más kafkiano de los sentidos, por lo que existen en la sociedad de manera liminal. Los personajes de "Ptosis", no tienen nombre. Él es el hijo de un fotógrafo que tiene como oficio fotografiar a personas que serán sometidas a operaciones de malformaciones en los ojos, ella es una paciente que tiene una deformidad en el párpado que "mostraba una sensualidad anormal" (18). El protagonista la fotografía en ausencia del padre, queda seducido por su defecto y dice, "le pedí que no cerrara los ojos para seguir disfrutando de esos tres milímetros suplementarios de párpado, esos tres milímetros de voluptuosidad desquiciante" (23). El día que finalmente ella se opera el queda "hecho añicos" (23) y escapa para no volver a verla. Más tarde se sabe que ha dejado el oficio de fotógrafo y que nunca regresa con su cámara al Sena, donde había paseado con la mujer, porque no "promete ya ningún misterio" (24).

El defecto físico erotiza al cuerpo y lo aísla de la mujer, para no ser considerado como un cuerpo socializado. La mujer no es amante, esposa o madre, funciones que en una sociedad patriarcal validan su identidad. Tampoco es cuerpo, es solo el objeto del deseo del hombres. El ojo deforme ayuda a la mujer a obtener a una pareja, pero la "normalidad" que recupera después de la operación, hace que lo pierda. Es lo que dice Bataille "lo que está siempre en cuestión es sustituir el asilamiento del ser, su discontinuidad, por un sentimiento de continuidad profunda" (cit en Lagarde 233).

El caso de "Ambliopía" es otro. Este cuento publicado también en Mudanzas traslada la soledad y el aislamiento de una niña bizca de un ojo en la fortaleza de quien logra independizarse de los otros. La protagonista es diagnosticada de ambliopíasíndrome del ojo flojo-y a partir de ahí debe llevar parchado el otro. Esta provoca 
una relación conflictiva entre ella y este, a quien describe como un ojo que pasea "repentinamente" sin llevarla a ella con él. "Un individuo aparte, un desconocido, un ojo vagabundo" (10). De esta manera lo personifica como un ente independiente de su cuerpo y se da cuenta de la fortaleza que este adquiere y que "envidio a los paseantes porque todo su cuerpo se adapta a la eventualidad, porque las cosas que piensan vienen de un sitio que está muy lejos o que ellos mismos fabrican sospechosamente. [...] Los envidio porque miran el mundo desde su catalejo y ordenan las manchas [...] Los envidio porque renuncian, porque son olvidados, porque son expulsados, porque se amparan en un devenir paralelo al del mundo o simplemente desisten de él y nunca usan anteojos (16)". La narración con un ritmo cortado como fluyendo de la conciencia habla de la homogeneidad y la normalidad como sospechosas y que termina por crear seres olvidados. Gerber establece también a partir de la metáfora del ojo una conexión entre lo extraño y el ejercicio de escribir. Esto se observa de igual forma en los textos que se analizan en la siguiente sección.

\subsubsection{La fragmentación del ejercicio literario. "Papiroflexia", "Telegrama" de Verónica Gerbery Los ingrávidos de Valeria Luiselli}

El libro de Verónica Gerber, Mudanza Auieo Ediciones: México 2010, se puede leer en línea. Es un libro de relatos cortos que revela dos aspectos de la escritora: su formación gráfica y su preparación literaria. Ella al igual que Luiselli aborda el conflicto de la escritura. "Papiroflexia" es la historia de Vito Acconci, escritor que decide dejar de escribir al terminar "una maestría en la Universidad de Iowa". (13). El cuento entremezcla poesía inspirada en el simbolismo con marcas de cosmopolitismo como frases en inglés para iniciar párrafos y paisajes urbanos. El problema del protagonista es el conflicto para llegar al lector, la pérdida de la autonomía que sufre el escritor y su angustia por no poder alcanzar la idea romántica del arte por el arte, fuera de todo realismo "quería que su historia fuera un suceso desplazado de la imaginación al mundo real " (20). Esta idea de la escritura como un fluido la retoma Gerber en "Telegrama" publicado en el mismo libro que inicia con la frase "La palabra es una entidad soluble". La historia habla de Ulises quien termina su doctorado en la Universidad de Leeds y es originario de San Andrés Tuxtla y nacido en 1941. El relato intercala conversaciones en formato telegráfico que nos refieren a la poesía simbolista. En él aparecen nombres como Pitol, del Paso, Elizondo, García Ponce, e incluso Octavio Paz, quien le escribe una carta. El conflicto es la imposibilidad de asir la palabra de darle materialidad a la vez de desdoblarla en el sentido saussurriano del signo en imágenes llenas de significados "Una imagen puede resonar en palabras, lo mismo que las palabras construyen imágenes" (38).

El siguiente ejemplo de este tema es Los ingrávidos (Sexto Piso 2011) de Luiselli, un ejemplo de un texto a temporal acerca de relaciones fragmentadas y espectrales entre la narradora, una escritora casada y con dos hijos, y Gilberto Owen, un poeta de la primera mitad del siglo XX. Volviendo brevemente a la biografía de la escritora diré que su éxito ha valido que su obra sea estudiada desde diversos aspectos. Yo me concentro en el acercamiento que hace del ejercicio creador con la manera en que las mujeres del siglo XXI negocian sus roles de madres, esposas, profesionistas, su 
propia sexualidad y sus espacios. La escritura denuncia la falta de un "cuarto propio" entendido en la idea de Virginia Wolfcomo el espacio aislado, íntimo y productivo del que carecen las mujeres, y dice "Antes escribía todo el tiempo, a cualquier hora, porque mi cuerpo me pertenecía. [...] Una novela silenciosa para despertar a los niños" (13). Hace referencia a los estados de la conciencia en donde lo onírico se mezcla con lo real, la renuncia al propio ser, en donde desfilan dentro de los recuerdos personajes de la literatura como Ezra Pound, o se hace referencia a Roberto Bolaño, quien se creyó que desataría un boom nuevo de la literatura latinoamericana. Solo quien ha leído a Rulfo entiende que la mujer que encuentra en la azotea a quien llama Dolores Preciado (34)refiere al lector al personaje de Pedro Páramo. La propia biografía de la escritora se ve en el contexto espacial de la historia, con referencias a lugares como la Universidad de Columbia. Los encuentros con Owen muestran la crisis que el escritor vive sin importar la barrera generacional y la forma en que intercala los diálogos fragmentados busca romper con toda línea temporal y representar más el estado de la conciencia.

Paz dice que "El lenguaje del poeta es el de su comunidad, cualquiera que esta sea. Entre uno y otro se establece un juego recíproco de influencias, un sistema de vasos comunicantes" (1998, p. 66) "El arco y la lira" La casa dela presencia. Poesía e historia. FCE México 1998. Eso es lo que sucede con estas cuatro escritoras, mismas que en la particularidad de cada una de sus obras establecen un diálogo con la literatura y una dinámica en donde tratan de romper con la narración lineal los lugares comunes, el tabú de no retratar su propia autobiografía. Incursionan en una serie de temas de manera universal a la vez que los presentan cuestionando la identidad y el estado de las cosas. Su preparación académica les ayuda a aportar nuevas epistemes y por tanto una manera particular de cumplir con su función creadora. Este trabajo aporta nombres de un (no) canon que debe recuperarse y sacarse a la luz. El trabajo que queda pendiente dentro de esta macro proyecto es el de una lectura transversal entre estas escritoras con formación superior y otras que no la tengan, para comparar temas, influencias, géneros literarios, propuestas y estilos.

\section{BIBLIOGRAFÍA}

\section{Libros completos:}

De Laurentis, Teresa. (1984). Alice Doesn't. Feminism, Semiotics, Cinema. Bloomington: Indiana UP.

Gerber, Verónica. (2010). Mudanza.México: Auieo Ediciones.

Lagarde, Marcela. (1993).Los cautiverios de las mujeres: madresposas, monjas, putas, presas y locas.México: UNAM.

Martínez, José Luis. (1993).La Expresión Nacional. México: CONACULTA.

Shaw, Donald L.(1999).Nueva Narrativa Hispanoamericana. Boom. Posboom. Posmodernismo. Madrid: Cátedra. 


\section{Artículos en papel y electrónicos:}

Canetti, Yanitzia. (2008). La literatura contemporánea víctima del despotismo comercial y la globalización en Montoya Juárez, Jesús \& Madrid, Ángel Esteban. (Eds.). en Montoya Juárez, Jesús E Esteban Ángel. (Eds.). Entre lo local y lo global. La narrativa latinoamericana en el cambio de siglo (1990-2006) (pp. 113128). Madrid, Frankfurt: Iberoamericana, Vervuert.

Cixous, Hélène. (1991).The Laugh of the Medusa, en Warhol, Robyn R. \& Diane Price Herndl (Eds.) Feminisms, an Anthology of Literary Theory and Criticism. (347-62). New Brunswick: Rutgers UP.

Damián Miravete, Gabriela. (2014). \#Readwomen2014: orgullo y prejuicios.Letras Libres. Marzo. Recuperado de:

http:/ / www.letraslibres.com/revista/letrillas/readwomen2014-orgullo-yprejuiciosd. Consultado el 15 julio 2015.

Didou Aupetit, Sylvie. (2015). Condiciones de género, escolaridad y ejercicio laboral entre las profesionistas.Revista de la educación superior (89). Recuperado de http:/ / www.anuies.mx. Consultado el 29 julio 2015.

Golubov, Nattie. (2011). La teoría literaria feminista y sus lectoras nómadas. Discurso, teoría y análisis (31), pp. 1-9.

Herber, Julián. (2011). Mudanza, de Verónica.Letras Libres. junio (11). Recuperado de: http:// www.letraslibres.com/revista/libros/mudanza-de-veronica-gerber. Consultado el: $1^{\circ}$ agosto 2015.

Herrera, Marina. (2008). El Cuerpo Incorrupto. Coahuila: La fragua. ---. (2015). El papel del escritor.Ediciones Global.(4 febrero). Recuperado de:

http:/ / www.vanguardia.com.mx/elpapeldelescritor-115202.html. Consultado el 15 julio 2015.

Hind, Emily. (2013).La generación XXX: entrevistas con veinte escritores mexicanos nacidos en los 70. De Abenshushan a Xoconostle. México: Ediciones Eón, Universidad veracruzana, U Wyoming.

Inegi. (2010). Caracterísitcas educativas de la población. INEGI 2010. Recuperado de: http:/ / www3.inegi.org.mx/ sistemas/temas/default.aspx?s=est\&c=19004 Consultado el: 6 ago 2015.

López Cuenca, Alberto. (2008). Formas de vida: de Wittgenstein a las comunidades electrónicas.A Parte Rei. Revista de filosofía. (56), (pp. 1-13). Recuperado de http:/ / serbal.pntic.mec.es/ AParteRei/. Consultado el: 16 julio 2015. 
Luiselli, Valeria. (2011). Los Ingrávidos. México: Sexto piso.

Nettel, Guadalupe. (2011). El cuerpo en que nací. Barcelona: Anagrama.

Noemí, Daniel. (2008). Y después de lo post, ¿qué? Narrativa latinoamericana hoy, en Montoya Juárez, Jesús \&Esteban Ángel. (Eds.). Entre lo local y lo global. La narrativa latinoamericana en el cambio de siglo (1990-2006) (83-98.). Madrid, Frankfurt: Iberoamericana, Vervuert.

Paz, Octavio. (1998). El arco y la lira.La casa de la presencia. Poesía e historia.(41-126). México FCE.

Rivera-Garza, Cristina. (2015). The New New Latino. Escribir desde el español en Estados Unidos Hoy.Revista Unidiversidad (17). Recuperado de http:/ / unidiversidad.com.mx/ the-new-new-latino-escribir-desde-el-espanolen-estados-unidos-hoy/.Consultado el 16 julio 2015.

Soriano, Michele. (2013). Cuestionamiento actuales de una norma cognitiva: género y discurso literario latinoamericano.García de la Sienra, Rodrigo; Quijano, Mónica Quijano \& Fenoglio, Irene (Eds.).La tradición teórico-crítica en América Latina: mapas y perspectivas (93-112). Bonilla Artigas.

Volpi, Jorge. (2008). Narrativa Hispanoamericana, Inc.en Montoya Juárez, Jesús \&Esteban Ángel. (Eds.). Entre lo local y lo global. La narrativa latinoamericana en el cambio de siglo (1990-2006) (83-98.). Madrid, Frankfurt: Iberoamericana, Vervuert.

\section{Autor}

\section{Adriana Pacheco Roldán}

Adriana Pacheco Roldán tiene un doctorado en Literatura y Culturas Ibero y Latinoamericana. Actualmente es profesora de tiempo completo en la Universidad de las Américas Puebla. Su área de investigación es la construcción y delimitación de la subjetividad e identidad femenina en discursos hegemónicos. Siglos XIX a XXI. 
Junio 2016 Año XIX (135) pp. 1- 16 